TI 2006-083/1

Tinbergen Institute Discussion Paper

Rent-seeking versus Productive Activities in a Multi-task Experiment

Hessel Oosterbeek

Randolph Sloof

Joep Sonnemans 


\section{Tinbergen Institute}

The Tinbergen Institute is the institute for economic research of the Erasmus Universiteit Rotterdam, Universiteit van Amsterdam, and Vrije Universiteit Amsterdam.

Tinbergen Institute Amsterdam

Roetersstraat 31

1018 WB Amsterdam

The Netherlands

Tel.: $\quad+31(0) 205513500$

Fax: $\quad+31(0) 205513555$

Tinbergen Institute Rotterdam

Burg. Oudlaan 50

3062 PA Rotterdam

The Netherlands

Tel.: $\quad+31(0) 104088900$

Fax: $\quad+31(0) 104089031$

Most TI discussion papers can be downloaded at http:/ /www.tinbergen.nl. 


\title{
Rent-seeking versus productive activities in a multi-task experiment*
}

\author{
Hessel Oosterbeek, Randolph Sloof ${ }^{\dagger}$ And Joep Sonnemans \\ University of Amsterdam \\ School of Economics \\ Roetersstraat 11 \\ 1018 WB Amsterdam \\ the Netherlands
}

September 24, 2006

\begin{abstract}
Incentive instruments like asset ownership and performance pay often have to strike a balance between the productive incentives and the rent-seeking incentives they provide. Standard theory predicts that a given instrument becomes less attractive when the effectiveness of rent-seeking activities increases. More recent theories that emphasize the importance of reciprocity, however, suggest that this relationship may go the other way around. In this paper we test these predictions by means of a laboratory experiment. By and large our findings confirm standard theory. Incentive instruments typically become less attractive when the scope for rent-seeking activities increases. However, reciprocity motivations do seem to mitigate the adverse effects of rent-seeking opportunities to a considerable extent.
\end{abstract}

Keywords: multi-task experiment, rent-seeking, reciprocity

JEL codes: C91, M52

\section{Introduction}

High-powered incentive instruments like ownership rights and pay-for-performance contracts are typically seen as suitable means to motivate hard work. A potential disadvantage of such in-

\footnotetext{
*An earlier version of this paper was presented at seminars at Royal Holloway (London), the University of Valencia, and at the ESA conference in Alessandria. The helpful remarks of Håkan Holm are gratefully acknowledged.

${ }^{\dagger}$ Corresponding author. e-mail: r.sloof@uva.nl; phone: +31 (0)20 5255241; fax: +31 (0)20 5254310.
} 
struments, however, is that they may also provide incentives to divert resources from productive activities. Take, for instance, performance pay. To motivate workers to put in effort, an organization may want to pay them on the basis of observed performance. In many cases, however, the organization's objective is not contractible and/or an undistorted performance measure is unavailable. The only alternative open is then to make use of a distorted performance measure, providing workers with incentives to 'game' the rewards system (cf. Holmstrom and Milgrom (1991); Baker (1992)). Gaming entails that workers optimize with respect to the actual performance measure rather than the intended (but non-contractible) objective. A telling example is provided by Jacob and Levitt (2003)'s empirical evaluation of the Chicago public school system over 1993-2000. They found that stronger teacher incentives significantly increased the observed frequency of teachers manipulating their students' test scores. ${ }^{1}$

Another example concerns asset (truck) ownership. Baker and Hubbard (2004) consider the relation between a truck driver and a truck dispatcher in which the driver makes two noncontractible decisions: (i) how much effort to expend in productive activities, viz. driving in ways that better preserve truck value and (ii) how much effort to expend in rent-seeking activities, like looking for alternative hauls that improve the driver's bargaining position vis-àvis the dispatcher. Driver ownership provides stronger incentives for both types of activities and thus outperforms dispatcher ownership only if the additional productive incentives it provides outweigh the extra rent-seeking incentives. In line with this, Baker and Hubbard find that when productive activities become better contractible through the introduction of on-board computers, ownership shifts from drivers towards dispatchers.

The above examples illustrate that incentive instruments often have to strike a balance between the productive incentives and the rent-seeking incentives they provide. Standard theory predicts that, if for a given instrument the effectiveness of rent-seeking activities increases, this instrument becomes less attractive as incentive device. This follows because agents are expected to shift resources from productive activities towards rent-seeking activities. Existing

\footnotetext{
${ }^{1}$ Courty and Marschke (2004)'s analysis of the Job Training Partnership Act provides another example of gaming. They find that training agencies strategically report the trainees' performance outcomes in order to maximize the yearly incentive awards. These timing responses create a welfare loss, because they appear to lower the effectiveness of training on enrollee earnings. Rather than simply accounting manipulations, the timing strategies thus do take away resources from productive activities.
} 
experimental evidence, however, suggests that this may not necessarily be the case. A large number of laboratory experiments have namely shown that reciprocity acts as an informal mechanism that stimulates productive effort c.q. investments; see e.g. Chapter 2 in Camerer (2003) for an overview. Choosing an effort/investment level larger than the individually rational one is seen as kind behavior, which is therefore rewarded with a larger than predicted return. This in turn makes it worthwhile to choose an effort/investment level higher than standard theory predicts. Now, the presence and effectiveness of rent-seeking activities could strengthen this informal mechanism. In particular, observing that a party does not engage in rent-seeking although it has ample opportunities to do so, may convince the other party that s/he is really fair and thus deserves a larger reward. And the more effective rent-seeking activities are, the better a signal of good intentions this under-utilization of rent-seeking possibilities becomes. This in turn may make it (even) more attractive to engage in productive activities. ${ }^{2}$ This paper reports an experiment designed to test this hypothesis.

Our experiment basically extends the well-known trust game of Berg et al. (1995) with a second investment opportunity. In the first stage of the game a seller chooses two investment levels, a productive one and an unproductive one. In the second stage a buyer then decides how much money to transfer back to the seller, where back transfers should be in between a minimum amount $M$ and the overall surplus $S$ (with $M<S$ ). Unproductive investments only affect $M$ and do not affect $S$. Productive investments increase $S$ and may also increase $M$, albeit to a much smaller extent. Within this setup we explore how the actual investments are affected when the sensitivity of the lower bound $M$ to the two types of investments is varied.

To the best of our knowledge, this is one of the first experiments that considers unproduc-

\footnotetext{
${ }^{2}$ Recent experimental studies by Fehr and Rockenbach (2003) and Fehr and List (2004) indeed find that simply having opportunities to behave unkindly but not using them may be efficiency enhancing. They compare the standard trust game of Berg et al. (1995) with a "trust with punishment" (TWP) treatment. In the former an investor first chooses transfer $p \in\{0,1, . ., 10\}$ to be sent to the trustee, together with a desired back transfer $\widehat{q} \leq 3 p$. The investment $p$ is tripled by the experimenter on the way. Subsequently, the trustee chooses the actual back transfer $q$, with $0 \leq q \leq 3 p$. In the TWP-treatment the investor also chooses whether to impose a fine of 4 on the trustee if $q<\widehat{q}$. The results show that back transfers are highest under TWP when no fine is imposed, lowest under TWP with the fine, and fall in between for the standard trust treatment. Moreover, investors who do not punish in TWP also invest a significantly larger amount than investors who impose the fine under TWP or investors in the standard trust game. The authors conclude that having the fining opportunity available but refraining from using it can signal good intentions. This in turn makes trustees more trustworthy and thereby strengthens investment incentives.
} 
tive investments within a multi-tasking environment. Some recent papers test the well-known prediction of tournament theory that a larger prize spread not only induces more productive effort, but also more destructive sabotage activities; see e.g. Harbring and Irlenbusch (2005) and Harbring et al. (2004). In contrast to our setup, however, these experiments do not include a subsequent transfer stage. The game ends after the (two types of) effort decisions have been made. Hence there is no role for the informal reciprocity mechanism as discussed above.

Fehr and Schmidt (2004) conduct a two-task principal-agent experiment in which the two tasks are complements. Efficiency therefore requires an even allocation of effort over the two tasks. However, only effort level $e_{1}$ in task one can be contracted upon. In the experiment the principal first chooses between a piece rate contract on $e_{1}$ and a bonus contract in which only a non-contractible bonus is promised. Subsequently the agent chooses effort levels $e_{1}$ and $e_{2}$. Finally, under the bonus contract the principal decides whether to pay (part of) the promised bonus. Standard theory predicts that the piece rate contract is chosen and that effort is allocated highly asymmetrically. The main findings, however, contradict these predictions. The bonus contract is chosen in $80 \%$ of the cases, effort allocation is much more even under the bonus contract, and the bonus contract strictly Pareto dominates the piece rate contract. Unlike Fehr and Schmidt's experiment, in our setting one type of effort constitutes a pure social waste. Moreover, we also consider the interplay between explicit and implicit incentives, by varying the degree to which good explicit incentive contracts are available.

The remainder of this paper is organized as follows. In the next section we discuss a simple model on which our experiment is based. This section also presents both the standard equilibrium predictions and some alternative predictions based on (intention-based) reciprocity. Section 3 describes our experimental design, while Section 4 discusses the results. The final section summarizes and concludes. 


\section{Theory}

\subsection{Basic setup of the model}

We first present the simple game on which our experiment is based, together with the standard equilibrium predictions. After that we discuss how it can be interpreted as a reduced form model of both (i) asset ownership and (ii) pay-for-performance as incentive devices. The next subsection derives alternative predictions based on intention-based reciprocity.

Consider a bilateral relationship between a male seller and a female buyer. Both parties are assumed to be risk neutral. The order of play is as follows:

1. The seller chooses investment levels $p$ and $u$, with $0 \leq p \leq \bar{p}$ and $0 \leq u \leq \bar{u}$. Costs of investment equal $C(p, u)=(p+u)^{2}$ and are immediately borne by the seller. Investment $p$ creates a gross surplus of $R(p)=R+r \cdot p$.

2. The buyer decides how much of the gross surplus $R(p)$ goes to the seller. The maximum amount she can give to the seller equals $R(p)$ whereas the minimum amount she has to give to the seller equals:

$$
\begin{aligned}
w(p, u) & =\pi \cdot R(p)+(1-\pi) \cdot Z(u) \\
& =\pi \cdot(R+r \cdot p)+(1-\pi) \cdot(Z+z \cdot u)
\end{aligned}
$$

In this game investment $p$ represents a productive investment, because it increases the gross surplus $R(p)$ up for division. Parameter $r \geq 0$ gives the constant marginal return to increases in $p$. Investment $u$ is an unproductive investment, as it does not affect $R(p)$ but only increases the minimum amount $w(p, u)$ the seller can secure for himself. Parameter $z \geq 0$ reflects the (gross) marginal returns to this type of investment. The minimum amount $w(p, u)$ is a weighted combination of the value of productive activities $R(p)$ and the value of rent-seeking activities $Z(u)$, where we assume that $R(p) \geq Z(u) \forall p, u \geq 0$ (i.e. $R(0) \geq Z(\bar{u})) .^{3}$ Following Holmstrom and Milgrom (1991) investment costs $C(p, u)$ are such that the two types of investment are

\footnotetext{
${ }^{3}$ The weight parameter $\pi \in[0,1]$ will be given an insightful interpretation in the next two subsections.
} 
Table 1: Equilibrium investment levels

\begin{tabular}{ccc}
\hline \hline Condition & $p^{*}$ & $u^{*}$ \\
\hline$(1-\pi) z>\pi r$ & 0 & $\frac{(1-\pi) z}{2}$ \\
$\pi r>(1-\pi) z$ & $\frac{\pi r}{2}$ & 0 \\
\hline \hline
\end{tabular}

Remark: The efficient investment levels equal $p_{e f f}=\frac{r}{2}$ and $u_{e f f}=0$.

perfect substitutes at the costs margin. They thus compete with each other for the same resources. Given these assumptions, the efficient investment levels equal $p_{\text {eff }}=\frac{r}{2}$ and $u_{\text {eff }}=0$.

The subgame perfect equilibrium predictions are easily derived. Assuming that seller and buyer are interested in their own monetary payoffs only, the buyer gives the seller the minimum amount $w(p, u)$ in the second stage. Anticipating this, the seller chooses those investment levels that maximize $w(p, u)-C(p, u)$. Table 1 characterizes these equilibrium investments $\left(p^{*}, u^{*}\right)$. In general, standard theory predicts underinvestment in the productive dimension and overinvestment in the unproductive dimension. Only when $\pi=1$ the seller obtains efficient investment incentives.

Our main interest lies in how investment levels vary with changes in $z$ and $\pi$ (relative to $r$ ). From Table 1 the following comparative statics predictions are easily obtained.

Standard theory Productive investments $p$ are (weakly) decreasing in $z$ and (weakly) increasing in $\pi$, while unproductive investments $u$ are (weakly) increasing in $z$ and (weakly) decreasing in $\pi$.

Intuitively these comparative statics can be understood as follows. When the (gross) marginal return $z$ to the unproductive investment increases, higher levels of $u$ become more attractive. Because the two types of investment compete for the same resources, productive investments then become less attractive. In a similar vein, the larger weight $\pi$ is, the bigger the share of the gross surplus $R(p)$ the seller can secure for himself. This makes productive investments $p$ more attractive and unproductive investments $u$ less so. 


\subsubsection{Asset ownership as incentive device}

A first interpretation of the model follows the property rights theory of the firm, see e.g. Baker et al. (2002) and Gibbons (2004). This theory builds on the idea that asset ownership provides incentives to make relationship-specific investments when contracts are incomplete. Once a party makes a specific investment, the investment is at risk because the other party may force a renegotiation of the deal. Anticipating that $\mathrm{s} /$ he cannot capture the full return, the investor will invest less than the efficient level. Asset ownership may alleviate this so-called holdup problem, because owning a critical asset implies that the investor has more bargaining power and thus can obtain a larger share of the ex post surplus. At the same time, however, the investor also obtains incentives to increase the asset's value in alternative, but inefficient uses. Asset ownership thus has both benefits and costs.

Our simple game can be interpreted as a holdup model in reduced form. After the seller has sunk his investments, buyer and seller bargain about the division of the ex post surplus $R(p)$ that materializes would they trade with each other. This surplus increases with the level of productive investments $p$ made. In case bargaining ends in disagreement, the parties do not trade and both receive the value of their respective alternative trading opportunities. For the buyer this outside value is normalized to zero. The seller's alternative opportunity is to sell his product on the outside market and yields him $Z(u)$. Higher values of unproductive investment $u$ improve the seller's outside opportunities and thereby his bargaining position vis-à-vis the buyer. Irrespective of the actual investments made, separation is never efficient though (i.e. $R(p) \geq Z(u) \forall p, u \geq 0)$.

Within the property rights literature it is typically assumed that the outcome of the bargaining equals the generalized Nash bargaining solution, see e.g. Hart (1995). Here this implies that the seller obtains a share equal to $w(p, u)$ as given in (1), with weight $\pi \in[0,1]$ reflecting his bargaining power. One interpretation of parameter $\pi$ is thus that it reflects the investor's bargaining power in a holdup context. Parameter $z$ then measures the (outside) marginal returns to investments in alternative trading opportunities. Using this interpretation, the main comparative statics prediction is that the lower the seller's bargaining power (lower $\pi$ ) or the 
more effective rent-seeking activities are (higher $z$ ), the more resources are shifted towards rent-seeking.

Although highly stylized, within the above model different ownership structures can be represented by different values of $z$ and $\pi$. Baker et al. (2002), for instance, compare two situations. Under (spot) outsourcing it holds that $\pi=\frac{1}{2}$ and $z>0$. In this case the seller owns the critical asset in production and the parties are non-integrated. The seller then has strong incentives to invest unproductively, especially when $z$ is high. The situation where the buyer owns the asset and the two parties are vertically integrated is labeled (spot) employment; the seller is simply an employee in this case. It then effectively holds that $\pi=z=0$ and the seller has no incentives to invest at all. Depending on how misaligned incentives under spot outsourcing are (i.e. how high $z$ is), the weak incentives under spot employment may either be more or less efficient than the strong but misaligned incentives under spot outsourcing.

More generally, seller ownership corresponds with higher values of both $z$ and $\pi$. The potential detrimental effects of ownership are represented by increases in $z$. These make investments $u$ in alternative uses of the asset more effective, which come at the expense of investments $p$ to specialize in the relationship. Asset ownership may thus have adverse effects on the incentives to specialize (cf. Rajan and Zingales (1998)). Increases in bargaining power $\pi$ represent the beneficial incentive effects of ownership. By owning the asset the seller also obtains stronger incentives to invest in its efficient use.

\subsubsection{Performance pay as incentive device}

A second interpretation results when the basic model is viewed in terms of a principal-agent relationship. A principal (buyer) hires an agent (seller) to perform a project for her. The project's value to the principal $R(p)$ depends on the amount of productive effort $p$ the agent exerts. Unfortunately, effort itself is non-contractible and also the undistorted performance measure $R(p)$ is unavailable. Performance pay can only be based on the distorted measure $w(p, u)$ given in (1). Here unproductive effort $u$ represents the degree to which the agent 'games' or manipulates the performance measure (cf. Holmstrom (1999)). For example, $u$ gives the degree to which the agent shades on quality. Alternatively, following Milgrom (1988) and 
Milgrom and Roberts (1988) $u$ can be interpreted as the level of influence activities an agent undertakes. Instead of focusing on productive activities in the current job, the agent may devote valuable time to building up credentials in order to enhance his future promotion possibilities.

Unlike in the previous subsection, an unambiguous interpretation of parameter $z$ independent of $\pi$ is less clear cut here. One possibility is that $z$ reflects the stake the agent has in manipulating the performance measure or in influencing the principal (e.g. the private value of promotion; cf. Milgrom (1988)), another one that it reflects his ability to do so. Parameter $\pi$ then gives the performance measure's sensitivity to manipulation c.q. the principal's susceptibility to influence activities. For instance, $\pi$ reflects the relative weight credentials take in the principal's promotion decision (cf. Milgrom and Roberts (1988)). Irrespective of the precise interpretation, the important thing to note is that the larger $z$ and the smaller $\pi$, the more $w(p, u)$ deviates from $R(p)$ and the more distorted the performance measure is. Only when $z=0$ or $\pi=1$ measure $w(p, u)$ is perfectly aligned. ${ }^{4}$

The order of play in the basic model assumes that the parties already signed an explicit pay-for-performance contract, stipulating that the agent's pay equals the objective performance measure $w(p, u)$. Given this existing contract, the agent first chooses the two effort levels $p$ and $u$. This secures him a contractual payoff of $w(p, u)$. On top of that the principal may, in the second stage, give the agent a discretionary bonus. The latter can be based on a subjective assessment of performance and thereby mitigate the potential detrimental effect of the distorted objective measure. This interpretation is in line with the model of Baker et al. (1994) in which such combinations of explicit and implicit contracts are analyzed in a repeated game setting. Clearly, this captures the principal-agent relationship in reduced form, because it takes the pay-for-performance contract as given. In a more elaborate model the principal would first choose her contract offer. Then, the more distorted performance measure $w(p, u)$ is, the weaker incentives are set in equilibrium. ${ }^{5}$ This follows because, according to standard theory, contracts

\footnotetext{
${ }^{4}$ For a slightly different setting with independent effort costs across tasks, Baker (2002) uses as measure of alignment the cosinus of the angle $\theta$ between the vector of marginals of firm value $R(p)$ and the vector of marginals of performance meausure $w(p, u)$, i.e. the angle between vectors $(r, 0)$ and $(\pi r,(1-\pi) z)$. For our case this yields $\cos (\theta)=\frac{\pi r}{\sqrt{\pi^{2} r^{2}+(1-\pi)^{2} z^{2}}}$, which is indeed decreasing in $z$ and increasing in $\pi$.

${ }^{5}$ When the principal is restricted to offer linear contracts of the form $W+\beta \cdot w(p, u)$, it can easily be derived that $\beta^{*}=\frac{r \cdot p^{*}}{2 \cdot C\left(p^{*}, u^{*}\right)} \leq \frac{1}{\pi}$. First best incentives require $\beta=\beta_{\text {eff }}=\frac{1}{\pi}$ (due to scaling, cf. Baker (1992, pp.
} 
that rely heavily on $w(p, u)$ become less attractive when $w(p, u)$ becomes more distorted. In our experiment the focus is on the latter prediction.

\subsection{Intention-based reciprocity}

Based on existing experimental evidence it was suggested in the Introduction that simply having better rent-seeking opportunities (but not using them) may be efficiency enhancing. For our simple game this intuition can be made formal using the theory of intention-based reciprocity of Dufwenberg and Kirchsteiger (2004). For ease of exposition we assume that the seller is selfish and motivated by money maximization only. The buyer may be motivated by reciprocity though, implying that she is willing to sacrifice to reward (punish) the seller's good (bad) intentions. In particular, her utility function equals:

$$
U_{B}=m_{B}+Y_{B} \cdot \kappa \cdot \lambda
$$

Here $m_{B}$ denotes the buyer's monetary payoffs and term $Y_{B} \cdot \kappa \cdot \lambda$ gives her reciprocity payoffs. Parameter $Y_{B} \geq 0$ reflects the buyer's reciprocal attitude. The larger $Y_{B}$, the more sensitive to reciprocity she is. Factor $\kappa$ measures the buyer's kindness towards the seller. It is positive if the buyer is kind to the seller and negative if she is unkind to him. Kindness is measured with reference to the range of payoffs $[w(p, u), R(p)]$ the buyer could give the seller in principle. Factor $\lambda$ gives the buyer's belief about how kind the seller is towards her. It is positive when the buyer believes the seller is kind to her, and negative when she thinks he is unkind. Dufwenberg and Kirchsteiger (2004) provide exact definitions of how $\kappa$ and $\lambda$ are calculated. A reciprocal buyer has an incentive to match the sign of her own kindness $\kappa$ with the sign of the perceived kindness $\lambda$ of the seller.

Because the reciprocity payoffs depend on the players' beliefs, psychological game theory is needed to derive equilibrium predictions. Within this framework Dufwenberg and Kirchsteiger define and prove the existence of a sequential reciprocity equilibrium (SRE). This concept requires each player to maximize his utility given correct beliefs and also invokes a subgame

603-604)). The ratio $\frac{\beta^{*}}{\beta_{e f f}}=\pi \cdot \beta^{*}$ is decreasing in $z$ and increasing in $\pi$, so the agent gets stronger incentives when the performance measure is better aligned. 
perfection requirement. The formal equilibrium analysis is relegated to Appendix A. Proposition 1 below summarizes the main predictions.

Proposition 1. Let $b(p, u)$ denote the bonus the buyer gives to the seller on top of $w(p, u)$. In (a sequential reciprocity) equilibrium it necessarily holds that:

$$
b(p, u)=\max \left\{0, R(p)-w(p, u)-[R(0)-w(0, \bar{u})]-\frac{2}{Y_{B}}\right\}
$$

Define $\bar{Y}(z, \pi) \equiv \frac{2}{\frac{r^{2}}{4}+(1-\pi) z \bar{u}-\left[\pi r p^{*}+(1-\pi) z u^{*}-C\left(p^{*}, u^{*}\right)\right]}$. The (generically) unique SRE-outcome is characterized by:

a) $Y_{B}<\bar{Y}(z, \pi)$ : the seller chooses $(p, u)=\left(p^{*}, u^{*}\right)$ and the buyer responds with $b\left(p^{*}, u^{*}\right)=0$;

b) $Y_{B}>\bar{Y}(z, \pi)$ : the seller chooses $(p, u)=\left(p_{e f f}, u_{e f f}\right)$ and the buyer responds with $b\left(p_{e f f}, u_{e f f}\right)$ $=(1-\pi) \cdot\left[\frac{r^{2}}{2}+z \cdot \bar{u}\right]-\frac{2}{Y_{B}}>0$.

From this proposition a number of interesting observations follow. First, in case $b(p, u)>0$ the equilibrium bonus payment can be rewritten as follows:

$$
b(p, u)=(1-\pi) \cdot[r p+z(\bar{u}-u)]-\frac{2}{Y_{B}}
$$

Hence, the higher $z$ and the lower $\pi$, the higher the bonus for a given investment combination $(p, u)$ is. The intuition here is that when $z$ is high and $\pi$ is low, the seller has better opportunities to signal good intentions through his investment choices. First consider variations in $z$. By under-utilizing rent-seeking opportunities (i.e. by choosing $u<\bar{u}$ ), the seller reveals his kindness. The larger $z$, the stronger this signal of kindness is. The seller is therefore rewarded more for a given investment combination $(p, u)$ when $z$ is higher. A similar reasoning applies for changes in $\pi$. By choosing a high $p$ and a low $u$ the seller signals good intentions. But the larger $\pi$ is, the more profitable a high $p$ and a low $u$ are for the seller himself (cf. Table 1 ). The signaling value of these choices is thus much lower and the buyer reduces the bonus payment in response. This explains why $b(p, u)$ decreases with $\pi$. 
Second, whenever a positive bonus is given, the seller's overall gross payoffs $w(p, u)+b(p, u)$ make him residual claimant of the gross surplus $R(p)$. This may give the seller the right (i.e. efficient) incentives to invest. For this to happen the buyer need to be sufficiently reciprocal (cf. case b)). If not (case a)), the equilibrium investments correspond to the ones obtained when the buyer is entirely selfish. The cutoff value $\bar{Y}(z, \pi)$ determines the scope for efficiency enhancing reciprocity. Corollary 1 establishes how this scope varies with $z$ and $\pi$.

Corollary 1. The cut-off value $\bar{Y}(z, \pi)$ is decreasing in $z$ and increasing in $\pi$. Hence the larger $z$ and the smaller $\pi$, the larger the scope for efficiency enhancing reciprocity is.

The way in which investment levels vary with changes in $z$ and $\pi$ is governed by two different forces. When the buyer is insufficiently reciprocal (cf. case a) in Proposition 1), the comparative statics as emphasized by standard theory pertain. A higher $z$ and a lower $\pi$ then make rentseeking activities directly more attractive, providing incentives to shift resources from productive investments towards unproductive ones. At the same time, however, Corollary 1 reveals that the seller is more easily persuaded to invest efficiently when $z$ is high and $\pi$ is low. That is, increases in $z$ and/or decreases in $\pi$ also make it more likely that case b) in Proposition 1 applies. ${ }^{6}$ The reason for this is that the seller gets better opportunities to signal good intentions, leading to higher and well-aligned bonus payments. Overall comparative statics depend on which of the two forces is strongest. Without precise information about the buyer's reciprocal attitude $Y_{B}$ no definite predictions can be made. The main point we want to make is that reciprocity motivations may potentially lead to comparative statics that are opposed to standard theory. This is summarized in the qualitative prediction below.

Reciprocity The scope for efficiency enhancing reciprocity is increasing in $z$ and decreasing in $\pi$. Productive investments $p$ may therefore increase with $z$ and decrease with $\pi$, while unproductive investments $u$ may decrease with $z$ and increase with $\pi$.

\footnotetext{
${ }^{6}$ Interpreted within the context of a principal-agent relationship, these comparative statics predict that stronger explicit incentives (lower $z$ and higher $\pi$ ) may crowd out implicit incentives based on an informal reciprocity mechanism. As shown by e.g. Baker et al. (1994) and Schmidt and Schnitzer (1995), a similar prediction may be obtained when the implicit incentives (i.e. non-contractible bonus payments) are backed by standard reputational considerations in a repeated game setting, rather than reciprocal motivations.
} 
Table 2: Treatments and standard predictions

\begin{tabular}{cccccc}
\hline \hline & $w(p, u)$ & $z$ & $\pi$ & $p^{*}$ & $u^{*}$ \\
\hline I & 0 & 0 & 0 & 0 & 0 \\
II & $4 \cdot u$ & 4 & 0 & 0 & 2 \\
III & $8 \cdot u$ & 8 & 0 & 0 & 4 \\
IV & $20+5 \cdot p$ & 0 & $\frac{1}{4}$ & $2 \frac{1}{2}$ & 0 \\
V & $20+5 \cdot p+3 \cdot u$ & 4 & $\frac{1}{4}$ & $2 \frac{1}{2}$ & 0 \\
VI & $20+5 \cdot p+6 \cdot u$ & 8 & $\frac{1}{4}$ & 0 & 3 \\
\hline \hline \multicolumn{2}{l}{$C(p, u)=(p+u)^{2}, R(p)=80+20 \cdot p$ and $Z(u)=z \cdot u$}
\end{tabular}

\section{Experimental design}

The experiment is based on a 3 by 2 design. We considered three different values of $z \in\{0,4,8\}$ and two different values of $\pi \in\left\{0, \frac{1}{4}\right\}$. The other parameters always equalled $R=80, r=20$ and $Z=0$. Investment levels $p$ and $u$ were restricted to integer values between 0 and 10 (hence $\bar{p}=\bar{u}=10)$. Similarly so, transfer payments in the second stage needed to be integer values as well and in between $w(p, u)$ and $R(p)$. Table 2 provides an overview of the six different treatments we considered together with the predicted investment levels under standard theory.

We ran six sessions in total. Three sessions considered the case $\pi=0$ and three other sessions the case $\pi=\frac{1}{4}$. All subjects within a session were confronted with all three values of $z$. Overall 120 subjects participated, with 20 participants per session. The subject pool consisted of the undergraduate student population of the University of Amsterdam. Most of them were students in economics. They earned on average 24.75 euros in slightly more than one hour.

Each session contained 15 rounds, which were divided into three blocks of five rounds each. Subjects kept the same role (either seller or buyer) during all these rounds. The experiment used a strangers design. Buyers and sellers were anonymously paired and their matching varied over the rounds. Within each block of five rounds subjects could meet each other only once. Subjects were explicitly informed about this. Moreover, within a session we divided the subjects into two groups of 10 subjects. Matching of pairs only took place within these groups. This 
yielded six independent observations per treatment at the aggregate group level.

Each block of five rounds considered one particular value of $z$. With three possible values for $z$, six potential orders exist. We designed the experiment such that for each level of $\pi$ we had one matching group that was confronted with a particular order of $z$ 's. For example, for $\pi=0$ one matching group was confronted with the order $(z=0, z=4, z=8)$ another one with $(z=8, z=0, z=4)$ etc.. With six matching groups per $\pi$-value, every order of $z$ 's was thus represented. In that way we controlled for order and learning effects.

The experiment was phrased neutrally. The seller was referred to as participant A, the buyer as participant B. Each round started with the seller choosing a column C (choice of $p$ ) and a row $\mathrm{R}$ (choice of $u$ ) in an 11 by 11 matrix. The cell so selected then reported in the upper left corner the minimum amount subject B had to return, in the upper right corner the maximum transfer, and below these two numbers the costs of this particular investment combination printed in red. Each block of five rounds used a different matrix, printed on papers of different colors (white, yellow, blue). To further avoid confusion, after each block we first collected the old matrix before handing out the new one.

From each block of five rounds we randomly selected one round that was actually paid. This was done after all 15 rounds were completed. One randomly selected subject threw a die three times to select the three payment rounds. Subjects learned which three rounds were selected and they obtained the number of points they had earned in these rounds, on top of their initial endowment of 200 points. (The conversion rate was one euro for 15 points.) Subjects were informed about this procedure at the start of the experiment. The rationale for paying only one round per block is that it further strengthens the one-shot nature of each interaction.

The experiment was computerized. Subjects started with on-screen instructions. Before the experiment started all subjects had to answer a number of control questions correctly. They also received a summary of the instructions on paper. At the end of the experiment subjects filled out a short questionnaire and the earned experimental points were exchanged for money. 


\section{Results}

The presentation of the empirical results is divided into three subsections. The first subsection deals with investment. The second subsection deals with back-transfers, markups and returns to investment. The third subsection connects investment and returns to investment.

\subsection{Investment}

We start with presenting average levels of productive investment $(p)$ and unproductive investment $(u)$ for each combination of $z$ and $\pi$, see Table 3 . This table also presents the results from tests of differences in investment levels within rows (same $\pi$, different $z$ ) and columns (same $z$, different $\pi$ ). These tests are based on mean investment levels per individual and per group. For ease of exposition only the significance levels are indicated; the exact $p$-values are reported in a web-appendix. ${ }^{7}$ Table 3 can be summarized by the following three results.

Result 1. Average productive investments are above their predicted levels and average unproductive investments are typically below their predicted levels.

Result 2. Average productive investments are (weakly) decreasing in $z$ whereas average unproductive investments are increasing in $z$.

Result 3. Average productive and unproductive investments are independent of $\pi$.

First consider the treatment with $\pi=0$ and $z=0$. Here the game boils down to a variation of the standard trust game. With $z$ equal to zero, unproductive investments receive no monetary reward and there is also no rationale for investments in $u$. (In only 5 out of 150 investment choices in this treatment, $u$ exceeds zero.) In order to choose a positive level of productive investment $p$, sellers need to trust that there is at least a positive probability that buyers reward the investment. Results from standard trust games typically show that investors do trust the receivers (and that receivers reward the investment). This is also true in our setting. In the treatment with $\pi=z=0$ the average productive investment $p$ equals 3.19 whereas 0 is predicted.

\footnotetext{
${ }^{7}$ This web-appendix is available at: www1.fee.uva.nl/scholar/mdw/sloof/Rentseeking_WebAppendix.pdf
} 
Keeping weight $\pi$ fixed at zero and increasing the (gross) marginal return $z$ to unproductive investments from 0 to 4 (and subsequently to 8) changes the seller's incentives. There is now an alternative investment opportunity with a guaranteed unit return of 4 (8). The second row in Table 3 shows that investors indeed start to invest positive amounts in $u$. These amounts, however, fall short of the predicted amounts, which are optimal given a choice of $p=0$. Due to the quadratic cost function $(p+u)^{2}$, positive amounts of $u$ increase the cost of investments in $p$, thereby making it more expensive for the seller to trust the buyer. It is therefore not surprising to observe that $p$ goes down as $z$ increases (although the decline is not significant for the change of $z$ from 0 to 4$)$.

The middle panel of Table 3 shows a very similar pattern for the treatments with $\pi=\frac{1}{4}$, both in absolute levels as well as in the comparative statics in $z$. For the treatment with $z=0$ and $\pi=\frac{1}{4}$, the average investment levels are virtually identical to those in the baseline treatment with $z=\pi=0$. Increases in the (gross) returns to unproductive investments $z$ are again accompanied by higher levels of $u$ and lower levels of $p$.

Theory predicts that productive investments (weakly) increase when $\pi$ increases from 0 to $\frac{1}{4}$. The reason is that the increase in $\pi$ raises the return to $p$ for the seller from 0 to 5 . This prediction is not supported by the results. For each level of $z$, average productive investments $p$ are constant in $\pi$. For $z$ equal to 4 and 8 there tends to be a small decline in unproductive investments $(u)$ when $\pi$ increases. The differences are, however, only significant at the level of individual means and not at the level of group means.

The previous results deal with the average levels of $p$ and $u$ separately. Our next result relates to the observed combinations of productive and unproductive investments.

Result 4. In all treatments, the theoretically predicted combination of $p$ and $u$ is the combination most frequently chosen.

This result follows from Tables 4 and 5 . These tables show frequencies of combinations of $p$ and $u$ for the different treatments; Table 4 considers the three treatments with $\pi=0$ and Table 5 the three treatments with $\pi=\frac{1}{4}$. In each treatment the total number of observed investment choices equals 150 . In all cases the highest frequency is observed for the theoretically predicted 
Table 3: Average investment levels $p$ and $u$ by treatment.

\begin{tabular}{|c|c|c|c|c|c|c|c|}
\hline & & $z=0$ & $z=4$ & $z=8$ & 0 vs. 4 & 0 vs. 8 & 4 vs. 8 \\
\hline \multirow[t]{4}{*}{$\pi=0$} & $p$ & $3.19[0]$ & $2.63[0]$ & $1.60[0]$ & - & $* * *$ & $* * *$ \\
\hline & & & & & - & \#\# & \#\# \\
\hline & $u$ & $0.09[0]$ & $0.86[2]$ & $2.82[4]$ & $* * *$ & $* * *$ & $* * *$ \\
\hline & & & & & \#\# & \#\# & \#\# \\
\hline \multirow[t]{4}{*}{$\pi=\frac{1}{4}$} & $p$ & $3.33\left[2 \frac{1}{2}\right]$ & $3.24\left[2 \frac{1}{2}\right]$ & $1.75[0]$ & - & $* * *$ & $* * *$ \\
\hline & & & & & - & \#\# & \#\# \\
\hline & $u$ & $0.12[0]$ & $0.56[0]$ & $2.22[3]$ & $* *$ & $* * *$ & $* * *$ \\
\hline & & & & & \#\# & \#\# & \#\# \\
\hline \multirow[t]{2}{*}{0 vs. $\frac{1}{4}$} & $p$ & - & - & - & & & \\
\hline & & - & - & - & & & \\
\hline \multirow[t]{2}{*}{0 vs. $\frac{1}{4}$} & $u$ & - & $* *$ & * & & & \\
\hline & & - & - & - & & & \\
\hline
\end{tabular}

Remark: Theoretically predicted investment levels in squared brackets. Symbols reflect significance levels obtained from signrank tests (for differences in $z$ ) and ranksum tests (for differences in $\pi$ ). For each comparison the upper (lower) significance levels are based on mean investment levels per subject (per group); ${ }^{* * *} / * * *$ (\#/\#\#/\#\#\#) indicates significance at the 10/5/1\%-level, - denotes insignificance. 
Table 4: Frequencies of $p$ and $u$ for $\pi=0$.

\begin{tabular}{|c|c|c|c|c|c|c|c|c|c|c|c|}
\hline \multirow{2}{*}{$\begin{array}{c}z=0 \\
u\end{array}$} & \multicolumn{11}{|c|}{$p$} \\
\hline & 0 & 1 & 2 & 3 & 4 & 5 & 6 & 7 & 8 & 9 & 10 \\
\hline 0 & 35 & 11 & 14 & 25 & 14 & 20 & 12 & 4 & 1 & 1 & 8 \\
\hline 1 & & & & 2 & & 1 & & & & & \\
\hline 2 & & & & & & & & & & & \\
\hline 3 & 1 & & & & & & & & & & \\
\hline 4 & & & & & & & & & & & \\
\hline 5 & & & & & & & & & & & \\
\hline 6 & & & & & & & & & & & \\
\hline 7 & 1 & & & & & & & & & & \\
\hline$z=4$ & & & & & & $p$ & & & & & \\
\hline$u$ & 0 & 1 & 2 & 3 & 4 & 5 & 6 & 7 & 8 & 9 & 10 \\
\hline 0 & 10 & & 8 & 12 & 19 & 15 & 7 & 7 & 1 & 3 & 1 \\
\hline 1 & 1 & 4 & 3 & 3 & & & 2 & 1 & & & \\
\hline 2 & 40 & 1 & 1 & 2 & 2 & & & & & & \\
\hline 3 & 5 & 1 & & & & & & & & & \\
\hline 4 & & & & & & & & & & & \\
\hline 5 & 1 & & & & & & & & & & \\
\hline$z=8$ & & & & & & $p$ & & & & & \\
\hline$u$ & 0 & 1 & 2 & 3 & 4 & 5 & 6 & 7 & 8 & 9 & 10 \\
\hline 0 & 3 & & 2 & 4 & 5 & 7 & 5 & 4 & 3 & & 1 \\
\hline 1 & 1 & 2 & 1 & 1 & & 2 & 2 & & & & \\
\hline 2 & 2 & 1 & 2 & 6 & & & & & & & \\
\hline 3 & 1 & 8 & 1 & & & & & 1 & & & \\
\hline 4 & 69 & 3 & & & & 1 & & & & & \\
\hline 5 & 6 & & & & & & & & & & \\
\hline 6 & 5 & & & & & & & & & & \\
\hline 7 & 1 & & & & & & & & & & \\
\hline
\end{tabular}

Remark: Predicted combinations in bold. Blanks indicate zero observations. 
combination(s) of $p$ and $u$. When $\pi=0$, the number of investment decisions in line with standard predictions goes from 35 to 40 to 69 when $z$ goes from 0 to 4 to 8 . When $\pi=\frac{1}{4}$ the corresponding figures are $69(22+47), 75(38+37)$ and 59 .

The two tables also show the directions of deviations from the point predictions. With $\pi=z=0$ (top panel in Table 4), $p=u=0$ is predicted. Indeed, for very few investment decisions $u$ exceeds 0 . In contrast, for a substantial number of investment decisions $p$ exceeds 0 . The most likely motive for sellers to choose $p>0$ is that they expect some return on their investment, thereby showing trust in the buyer. An alternative motive might be that sellers want to maximize overall efficiency rather than their own monetary payoffs. Sellers with this motive ought to choose $p=10$. This is, however, not something commonly observed in any of the treatments.

With $\pi=0$ and $z=4$ (middle panel in Table 4), the predicted investments equal $p=0$ and $u=2$. While this combination is indeed the modal choice, many sellers choose $p>0$ (and $u<2$ ) thereby revealing some trust in the buyer. The same pattern emerges for $\pi=0$ and $z=8$ (lower panel in Table 4). The predicted combination of $p=0$ and $u=4$ attracts almost $50 \%$ of the choices. Deviations are typically in the direction of lower $u$ and higher $p$.

When $\pi=\frac{1}{4}$ the seller has a guaranteed unit return of 5 on productive investments. For $z=0$ and $z=4$ (both less than 5), this makes the choices of $u=0$ and $p=2$ or $p=3$ optimal, unless buyers reward higher levels of productive investment. Interestingly, while in the $\pi=z=0$ treatment 113 out of 150 investment choices involve a higher level of $p$ than predicted, in the $\left(\pi=\frac{1}{4}, z=0\right)$-treatment, only 57 out of 150 reveal such trust. In the $\left(\pi=\frac{1}{4}, z=4\right)$-treatment this is only 46 .

In the $\left(\pi=\frac{1}{4}, z=8\right)$-treatment, the private unit return to $u$ equals $6\left(=\left(1-\frac{1}{4}\right) \cdot 8\right)$ and thus exceeds the guaranteed return to $p$ of 5 . It is therefore predicted that investors solely invest in $u$ and not in $p$, with the optimal amount of unproductive investment equal to 3 . The lower panel of Table 5 shows that 59 out of 150 investment choices in this treatment concur with this prediction. Deviations are typically in the direction of lower $u$ and higher $p$, thereby expressing sellers' belief that buyers may reward their productive investment. In over $10 \%$ of the cases, however, sellers choose a level of $u$ above the predicted level (suggesting that they miscalculate). 
Table 5: Frequencies of $p$ and $u$ for $\pi=\frac{1}{4}$.

\begin{tabular}{|c|c|c|c|c|c|c|c|c|c|c|c|}
\hline \multirow{2}{*}{$\begin{array}{c}z=0 \\
u\end{array}$} & \multicolumn{11}{|c|}{$p$} \\
\hline & 0 & 1 & 2 & 3 & 4 & 5 & 6 & 7 & 8 & 9 & 10 \\
\hline 0 & 13 & 7 & 22 & 47 & 17 & 21 & 7 & 4 & 2 & & 2 \\
\hline 1 & & 1 & 1 & & & & & 1 & & & \\
\hline 2 & & & 1 & & 1 & & & & & & \\
\hline 3 & 1 & & & & & & & & 1 & & \\
\hline 4 & & & & & & & & & & & \\
\hline 5 & & & & & 1 & & & & & & \\
\hline$z=4$ & & & & & & $p$ & & & & & \\
\hline$u$ & 0 & 1 & 2 & 3 & 4 & 5 & 6 & 7 & 8 & 9 & 10 \\
\hline 0 & 2 & 2 & 38 & 37 & 7 & 8 & 11 & 6 & 4 & 1 & 2 \\
\hline 1 & 3 & 3 & 1 & 2 & & & & & & & \\
\hline 2 & 3 & 1 & 1 & & & & & & & & \\
\hline 3 & 11 & & & & & & 1 & & 1 & & \\
\hline 4 & & & & & & & & & & & \\
\hline 5 & & & & & 1 & 1 & & & 1 & 1 & \\
\hline 6 & & & & & & & 1 & & & & \\
\hline$z=8$ & & & & & & $p$ & & & & & \\
\hline$u$ & 0 & 1 & 2 & 3 & 4 & 5 & 6 & 7 & 8 & 9 & 10 \\
\hline 0 & 3 & & & 12 & 5 & 11 & 10 & 2 & 1 & 1 & \\
\hline 1 & & & 2 & & & & & & & & \\
\hline 2 & 2 & 9 & 3 & & & 1 & & & & & \\
\hline 3 & 59 & & 2 & 5 & 1 & & & & & & \\
\hline 4 & 4 & & & & 2 & & & & & & \\
\hline 5 & 13 & & 1 & & & & & & & & \\
\hline 6 & & & & 1 & & & & & & & \\
\hline
\end{tabular}

Remark: Predicted combinations in bold. Blanks indicate zero observations. 


\subsection{Back-transfers and markups}

We now turn to the analysis of the back-transfers buyers pay to sellers. Table 6 reports for all treatments the mean values of various components of parties' payoffs, with in square brackets predictions from standard theory. The minimum back-transfer the seller can guarantee himself equals $w(p, u)$ (see Table 2). For the theoretically predicted investment choices of $p$ and $u$, this expression increases in $z$ and $\pi$. The rows with entry $w(p, u)$ show that this is also the case for the actual average minimum back transfers. Note that $w(p, u)$ is just a particular weighted combination of the actual investments chosen, with the weights depending on $z$ and $\pi$. Comparative statics in $z$ and $\pi$ thus result from both exogenous variations (through the weights) and endogenous ones (through the investments chosen). Therefore, the findings on $w(p, u)$ partly replicate our earlier findings on investments. Deviations from predicted minimum transfers are fully attributable to differences between predicted and actual investment choices.

Standard theory predicts that buyers will refrain from giving sellers a markup above the minimum back-transfer $w(p, u)$. The results in the rows labeled "Markup" show that this prediction is not borne out by the data. When $\pi=0$ the average markup is between 16 and 30

and (weakly) decreases in $z$. For $\pi=\frac{1}{4}$ the average markup is substantially lower and around 5 , independent of $z$. Ranksum tests (reported in the web-appendix) reveal that markups decrease in $\pi$ for any given level of $z$. Note that, because buyers have full discretion over the markup, any variation with $z$ and $\pi$ is fully endogenous. We summarize these findings in the following result:

Result 5. The average markup is positive and (a) (weakly) decreases with $z$ for $\pi=0$, (b) is constant in $z$ for $\pi=\frac{1}{4}$, and (c) decreases in $\pi$.

Table 6 also reports the average total transfer for each treatment. The total transfer equals the sum of the minimum back-transfer and the markup. Overall the test statistics reveal that the total transfer does not vary with the level of $z$ (although the tests performed at the individual level suggest a weakly increasing relationship). However, total transfers do appear to increase in $\pi$ (cf. the web-appendix). This indicates that the overall effects of $z$ and $\pi$ on $w(p, u)$ dominate their effects on the markup. Hence, the fact that in deviation from standard 
Table 6: Average back transfers, markups and earnings by treatment

\begin{tabular}{|c|c|c|c|c|c|c|c|}
\hline & & $z=0$ & $z=4$ & $z=8$ & 0 vs. 4 & 0 vs. 8 & 4 vs. 8 \\
\hline \multirow[t]{12}{*}{$\pi=0$} & $w(p, u)$ & 0 & 3.4 & 22.6 & $* * *$ & $* * *$ & $* * *$ \\
\hline & & {$[0]$} & {$[8]$} & {$[32]$} & \#\# & \#\# & \#\# \\
\hline & Markup & 30.2 & 26.8 & 16.7 & - & $* * *$ & $* * *$ \\
\hline & & {$[0]$} & {$[0]$} & {$[0]$} & - & \#\# & \# \\
\hline & Transfer & 30.2 & 30.2 & 39.3 & - & $* *$ & $* * *$ \\
\hline & & {$[0]$} & [8] & {$[32]$} & - & - & - \\
\hline & Earn. seller & 12.1 & 13.8 & 17.5 & - & $* *$ & $*$ \\
\hline & & {$[0]$} & {$[4]$} & {$[16]$} & - & \# & - \\
\hline & Earn. buyer & 113.5 & 102.4 & 72.7 & $* * *$ & $* * *$ & $* * *$ \\
\hline & & {$[80]$} & {$[72]$} & {$[48]$} & \#\# & \#\# & \#\# \\
\hline & Tot. earn. & 125.6 & 116.2 & 90.2 & $* * *$ & $* * *$ & $* * *$ \\
\hline & & {$[80]$} & {$[76]$} & [64] & \# & \#\# & \#\# \\
\hline \multirow[t]{12}{*}{$\pi=\frac{1}{4}$} & $w(p, u)$ & 36.5 & 37.8 & 41.7 & - & $* * *$ & $* * *$ \\
\hline & & [32.5] & {$[32.5]$} & {$[38]$} & - & \#\# & - \\
\hline & Markup & 5.8 & 6.0 & 4.5 & - & - & - \\
\hline & & {$[0]$} & {$[0]$} & {$[0]$} & - & - & - \\
\hline & Transfer & 42.4 & 43.9 & 46.5 & - & $* *$ & $* *$ \\
\hline & & {$[32.5]$} & [32.5] & {$[38]$} & - & - & - \\
\hline & Earn. seller & 26.2 & 23.2 & 28.4 & - & - & $* * *$ \\
\hline & & {$[26.25]$} & {$[26.25]$} & {$[29]$} & - & - & - \\
\hline & Earn. buyer & 104.1 & 100.9 & 68.4 & - & $* * *$ & $* * *$ \\
\hline & & {$[97.5]$} & {$[97.5]$} & {$[42]$} & - & \#\# & \#\# \\
\hline & Tot. earn. & 130.3 & 124.1 & 96.8 & ** & $* * *$ & $* * *$ \\
\hline & & [123.75] & [123.75] & {$[71]$} & - & \#\# & \#\# \\
\hline
\end{tabular}

Remark: Theoretical predictions in squared brackets. Symbols reflect significance levels obtained from signrank tests. For each comparison the upper (lower) significance levels are based on mean investment levels per subject (per group); ${ }^{*}{ }^{* *} /{ }^{* * *}$ (\#/\#\#/\#\#\#) indicates significance at the 10/5/1 \%-level, - denotes insignificance. 
theoretical predictions buyers pay sellers a markup, does not alter the predicted pattern of the total transfers.

Because investors typically invest more in $p$ and less in $u$ than predicted (cf. Result 1), realized net total earnings exceed the predicted levels, especially when $\pi=0$ (cf. Table 6). And because buyers typically pay sellers some markup, both parties appear to benefit from these deviations from standard theory. Both the buyer's earnings and joint earnings are (weakly) decreasing in $z$ and constant in $\pi$. The former finding is in line with standard theory, the latter is not. The buyer was expected to earn less when $\pi$ increases whereas total earning earnings were predicted to increase. In line with standard theory, however, the seller benefits from having a higher $\pi$. He also benefits from a higher $z$. According to standard theory this ought to be the case because a higher $z$ increases the (gross) return to the unproductive investment. With reciprocity motivations this could be the case if buyers pay a higher markup return to productive investments when $z$ increases. We next investigate whether this latter mechanism operates.

Table 7 analyzes for each treatment separately how the markup is related to the choices of $p$ and $u$. Because back-transfers are restricted to be at least as large as $w(p, u)$, observed backtransfers are censored at this point. This translates into the markup not being smaller than zero. To accommodate this feature of the data, we estimated tobit models. Let $y^{*}+w(p, u)$ denote the amount which the buyer wants to pay back to the seller. The rules of the game specify that the actual $y$ 's should be non-negative, i.e. $y \geq 0$. Hence back-transfers of buyers who wanted to transfer less than $w(p, u)$ are censored at $w(p, u)$. The relation between observed actual $y$ 's and intended latent $y^{*}$ 's is then: ${ }^{8}$

$$
\begin{aligned}
& y=y^{*} \text { if } y^{*}>0, \\
& y=0 \text { if } y^{*} \leq 0 .
\end{aligned}
$$

For each buyer we observe five back-transfer decisions per level of $z$. This allows us to include unobservable individual effects. Since the levels of $p$ and $u$ are uncorrelated with these

\footnotetext{
${ }^{8}$ Strictly speaking there is also right hand censoring as the back-transfer cannot exceed $R(p)$. Because buyers never transfer this maximum amount, this restriction is not binding and we therefore ignore it in our estimates.
} 
unobservable individual effects (because $p$ and $u$ are chosen by the seller without knowing the buyer's identity), we do this by estimating random effects models instead of fixed effects models. ${ }^{9}$

Table 7 reports three different estimates of the effects of both types of investment. Columns (1) and (2) report the effects of changes in $p$ and $u$ on the expected value of the (unobserved) amount that the buyer wanted to pay to the seller if there would be no restriction in the form of a lower limit. Columns (3) and (4) report the effects of changes of $p$ and $u$ on the observed markup. ${ }^{10}$ Finally, columns (5) and (6) give the effects of $p$ and $u$ on the observed markup given that the markup is positive. ${ }^{11}$

The results in Table 7 clearly indicate that buyers do pay sellers a return on their productive investment. High levels of $p$ increase the (intended) markup. In all six treatments (combinations of $\pi$ and $z$ ), the estimates of the effects of $p$ are significantly different from zero at the $5 \%$-level. In contrast, in five out of six treatments the estimated effects of $u$ are not significantly different from zero. This suggests that buyers do not punish sellers for their, presumably unkind, choice of positive $u$. There is, however, one exception: sellers who invest in $u$ in treatment III are punished for doing so.

The effects of $p$ and $u$ on the actual markup are smaller than the effects on the intended markup. This is because increases in the intended markup are not (fully) transmitted to the actual markup if the intended markup was smaller than zero. The ratio between the effects in columns (3) and (4) and these in columns (1) and (2) is around 0.52. The ratio between the effects in columns (5) and (6) and those in columns (1) and (2) is around 0.37. The patterns and significance levels of the effects in columns (3) through (6) are identical to the ones in columns (1) and (2).

Result 6. The markup depends positively on $p$ and is independent of $u$.

We tested for equality of the effects of $p$ and $u$ on the markup for different values of $z$ and

\footnotetext{
${ }^{9} \mathrm{An}$ additional reason is that with only five observations per subject fixed effects estimates suffer from the incidental parameter problem.

${ }^{10}$ These estimates are obtained by multiplying the coefficients for $p$ and $u$ in columns (1) and (2) by $\Phi\left(\frac{X^{\prime} b}{\sigma}\right)$.

${ }^{11}$ These estimates are obtained by multiplying the coefficients for $p$ and $u$ in columns (1) and (2) by $\left(1-\frac{X^{\prime} b}{\sigma} \cdot \frac{\phi\left(\frac{X^{\prime} b}{\sigma}\right)}{\Phi\left(\frac{X^{\prime} b}{\sigma}\right)}-\left(\frac{\phi\left(\frac{X^{\prime} b}{\sigma}\right)}{\Phi\left(\frac{X^{\prime} b}{\sigma}\right)}\right)^{2}\right)$, see Maddala (1983, p. 160).
} 
Table 7: Effects of $p$ and $u$ on the markup; random effects tobit estimates

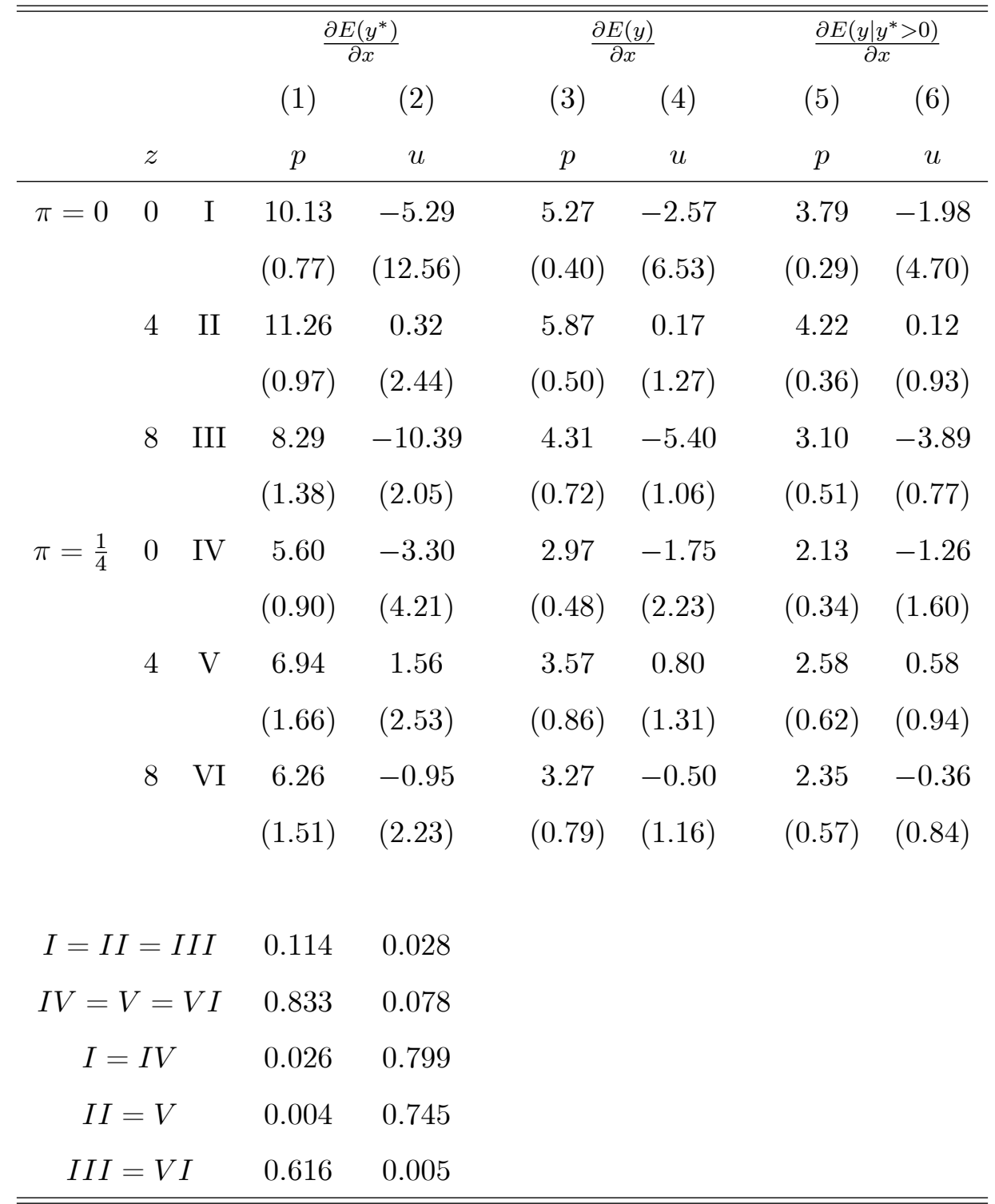

Remark: Standard errors appear in parentheses. The last six rows present $p$-values from likelihood ratio tests on the equality of estimated coefficients (for $p$ and $u$ separately) across treatments. 
given values of $\pi$, see the bottom rows in Table 7. It appears that markup returns to $p$ do not vary with $z$. Markup returns to $u$ are independent of $z$ if $\pi=\frac{1}{4}$ and vary with $z$ if $\pi=0$. The pattern in this last case is, however, not monotonic. By and large the markup returns to $u$ are independent of $z$. We also tested for equality of the effects of $p$ and $u$ on the markup for different values of $\pi$ and given values of $z$. For $z=0$ and $z=4$ returns on $p$ are decreasing in $\pi$; for $z=8$ returns on $u$ are increasing in $\pi$.

Result 7. The markup returns on $p$ and $u$ are independent of $z$. The markup returns on $p$ are (weakly) decreasing in $\pi$ and the markup returns on $u$ are (weakly) increasing in $\pi$.

Result 7 is partly consistent with the predictions based on intention-based reciprocity. From expression (3) in Section 2 the expected markup return to $p$ equals 20(1- $\pi$ ) (assuming that the markup is positive). As explained there, the lower $\pi$ the stronger a signal of kindness a given productive investment $p$ is. A reciprocal buyer will therefore give a larger bonus in response. This is in line with what we observe, although the actual impact of changes in $\pi$ is much smaller than predicted; the actual markup return figures around $3 \frac{1}{2}(1-\pi)$. Also in line with reciprocity, the actual returns on $p$ in the markup are independent of $z$.

The expected return on $u$ in the markup equals $-z(1-\pi) \cdot u$ (cf. expression (3)). Note that this return is always negative. The seller is thus always punished for choosing high(er) values of $u$, but less so when $\pi$ is high or $z$ is low. We do indeed observe that markup returns are weakly increasing in $\pi$. However, they do not vary with $z$, although reciprocity predicts a decreasing relationship whenever $\pi<1$. Apparently, buyers fail to recognize that a given investment level $u$ is more unkind when $z$ increases. (The latter is the flip side of the fact that a given level of under-utilization of rent-seeking possibilities $(\bar{u}-u)$ is more kind the higher $z$ is.)

Result 7 lends some support to the prediction that better explicit incentives may partially crowd out implicit incentives based on an informal reciprocity mechanism. When the performance measure becomes better aligned, i.e. $\pi$ increases, the performance payment $w(p, u)$ the agent gets provides him with stronger incentives to invest productively. At the same time, however, the impact of $\pi$ on the non-contractible bonus payment reduces his incentives to do so. Explicit incentives thus partially crowd out implicit incentives. This finding is in line with a 
finding reported Fehr et al. (2004). They study how concerns for fairness affect the actual choice of contracts in a principal-agent relationship. Among the contracts considered are pure bonus contracts in which the principal can only pay a non-contractible bonus ex post and combined incentive-bonus contracts in which explicit (ex ante) incentives can be given besides the bonus. They find that in the combined contracts principals reward high effort levels less generously than in pure bonus contracts, i.e. combined contracts provide lower implicit incentives.

\subsection{Investment and returns to investment}

Standard theory predicts that sellers' net earnings equal $w(p, u)-(p+u)^{2}$. This implies that for given $z$ and $\pi$, the sellers' payoffs are a (sometimes degenerate) function of $p, u, p^{2}, u^{2}$ and $p \cdot u$. The same holds with respect to the reciprocity predictions. For each treatment, we regressed sellers' payoffs on these variables. Results are presented in Table $8{ }^{12}$ In square brackets, Table 8 also reports the theoretically predicted effects of the various regressors based on standard theory.

We tested whether the estimated coefficients are jointly significantly different from their predicted values. For all six regressions we had to reject the hypothesis of no difference at the 1\%-level. In spite of this, many of the separate coefficients are fairly close to the predicted values and not significantly different from these. The coefficients that are significantly different (at the $5 \%$-level) from their predicted values are marked with an asterisk $\left(^{*}\right)$.

The final two columns of Table 8 report the "optimum" levels of $p$ and $u$ for the seller, given the estimated payoff functions. These levels were calculated by comparing the payoffs for all 121 possible $(p, u)$-combinations. These columns also repeat the actual average investment levels (in curly brackets) and the investment levels predicted by standard theory (in square brackets). In most treatments deviations of actual investment levels from theoretically predicted levels square well with the "optimum" levels. For instance, for treatment I theory predicts $p=u=0$ whereas "optimum" levels are $p^{*}=4$ and $u^{*}=0$. Actual investment in $p$ is in the direction of 4 (3.19) while the actual $u$ investment is basically zero. The main deviation is observed for treatment

\footnotetext{
${ }^{12}$ We could of course also have estimated regressions of investors payoffs on $p, u$ and $(p+u)^{2}$. The current specification is more flexible because it allows different combinations of $p$ and $u$ that lead to the same cost level, to have different effects on payoffs.
} 
Table 8: Effects of $p$ and $u$ on sellers' net earnings

\begin{tabular}{|c|c|c|c|c|c|c|c|c|c|c|}
\hline & $z$ & & const. & $p$ & $u$ & $p^{2}$ & $u^{2}$ & $p \cdot u$ & $p^{*}$ & $u^{*}$ \\
\hline \multirow{9}{*}{$\pi=0$} & 0 & I & 1.80 & $10.00^{*}$ & 5.12 & -1.19 & -1.80 & -6.31 & 4 & 0 \\
\hline & & & $(2.40)$ & $(3.49)$ & $(7.34)$ & $(0.52)$ & $(1.05)$ & $(5.42)$ & $\{3.19\}$ & $\{0.09\}$ \\
\hline & & & {$[0]$} & {$[0]$} & {$[0]$} & {$[-1]$} & {$[-1]$} & {$[-2]$} & {$[0]$} & {$[0]$} \\
\hline & 4 & II & 6.25 & 4.31 & 3.74 & $-0.18^{*}$ & -1.09 & -5.05 & 10 & 0 \\
\hline & & & $(4.68)$ & $(2.81)$ & $(3.62)$ & $(0.38)$ & $(0.68)$ & $(2.18)$ & $\{2.63\}$ & $\{0.86\}$ \\
\hline & & & {$[0]$} & {$[0]$} & {$[4]$} & {$[-1]$} & {$[-1]$} & {$[-2]$} & {$[0]$} & {$[2]$} \\
\hline & 8 & III & -5.75 & $18.32^{*}$ & 11.82 & $-2.08^{*}$ & -1.51 & $-4.67^{*}$ & 4 & 0 \\
\hline & & & $(6.54)$ & $(3.34)$ & $(2.85)$ & $(0.29)$ & $(0.33)$ & $(0.82)$ & $\{1.60\}$ & $\{2.82\}$ \\
\hline & & & {$[0]$} & {$[0]$} & {$[8]$} & {$[-1]$} & {$[-1]$} & {$[-2]$} & {$[0]$} & {$[4]$} \\
\hline \multirow{9}{*}{$\pi=\frac{1}{4}$} & 0 & IV & 21.4 & 5.46 & -0.67 & -0.79 & -0.52 & $-2.78^{*}$ & 3 & 0 \\
\hline & & & $(1.63)$ & $(1.23)$ & $(2.46)$ & $(0.21)$ & $(0.62)$ & $(0.33)$ & $\{3.33\}$ & $\{0.12\}$ \\
\hline & & & {$[20]$} & {$[5]$} & {$[0]$} & {$[-1]$} & {$[-1]$} & {$[-2]$} & {$[2.5]$} & {$[0]$} \\
\hline & 4 & $\mathrm{~V}$ & 21.66 & 5.54 & 8.17 & -0.91 & $-3.51^{*}$ & $0.03^{*}$ & 3 & 1 \\
\hline & & & $(3.91)$ & $(2.34)$ & $(3.18)$ & $(0.27)$ & $(0.97)$ & $(0.55)$ & $\{3.24\}$ & $\{0.56\}$ \\
\hline & & & {$[20]$} & {$[5]$} & {$[3]$} & {$[-1]$} & {$[-1]$} & {$[-2]$} & {$[2.5]$} & {$[0]$} \\
\hline & 8 & VI & 22.44 & 1.07 & 6.69 & 0.10 & -1.27 & -1.69 & 0 & 3 \\
\hline & & & $(4.40)$ & $(4.41)$ & $(1.96)$ & $(0.71)$ & $(0.22)$ & $(0.53)$ & $\{1.75\}$ & $\{2.22\}$ \\
\hline & & & {$[20]$} & {$[5]$} & {$[6]$} & {$[-1]$} & {$[-1]$} & {$[-2]$} & {$[0]$} & {$[3\}$} \\
\hline
\end{tabular}

Remark: below the coefficients are the robust standard errors in parentheses and the predicted effects in square brackets. Coefficients that differ significantly (at the 5\%-level) from the predicted coefficients are marked with an ${ }^{*} . p^{*}$ and $u^{*}$ give the 'optimum' investment levels, i.e. the combination of $p, u \in\{0,1,2,, 10\}$ that gives the highest net payoff to the seller given estimated coefficients. Below $p^{*}$ and $u^{*}$ are average actual investment levels in curly brackets and theoretically predicted levels (based on standard theory) in square brackets. 
VI. Here the "optimum" levels coincide with the theoretically predicted levels $(p=0, u=3)$, but actual investment patterns show positive investment in $p$.

\section{Conclusion}

In this paper we explore, within a multi-task experiment, how incentives to engage in productive activities are affected when the marginal returns to unproductive rent-seeking activities increase. Standard theory predicts a negative relationship whereas reciprocity considerations suggest that productive activities are unaffected or may even increase. The intuition behind this latter prediction is that better rent-seeking opportunities also improve opportunities for signaling good intentions. This may strengthen an informal reciprocity mechanism under which productive activities are rewarded with a higher than predicted return.

Our findings reveal that subjects typically choose higher rent-seeking levels when the marginal returns to rent-seeking increase. The observed increases, however, are much smaller than standard theory predicts and often lack significance. Moreover, investments in productive activities are typically higher than standard theory predicts and investments in rent-seeking usually lower. Reciprocity considerations thus seem to mitigate the adverse affects of rent-seeking opportunities. Yet they do not completely eliminate them.

\section{References}

Baker, G. (1992). Incentive contracts and performance measurement. Journal of Political Economy 100, 598-614.

Baker, G. (2002). Distortion and risk in optimal incentive contracts. Journal of Human Resources 37, 728-751.

Baker, G., R. Gibbons, and K. Murphy (1994). Subjective performance measures in optimal incentive contracts. Quarterly Journal of Economics 109, 1125-1156.

Baker, G., R. Gibbons, and K. Murphy (2002). Relational contracts and the theory of the firm. Quarterly Journal of Economics 116, 39-84. 
Baker, G. and T. Hubbard (2004). Contractibility and asset ownership: On-board computers and governance in U.S. trucking. Quarterly Journal of Economics 119, 1443-1479.

Berg, J., J. Dickhaut, and K. McCabe (1995). Trust, reciprocity, and social history. Games and Economic Behavior 10, 122-142.

Camerer, C. (2003). Behavioral game theory. Experiments in strategic interaction. Princeton University Press.

Courty, P. and G. Marschke (2004). An empirical investigation of gaming responses to explicit performance incentives. Journal of Labor Economics 22, 23-56.

Dufwenberg, M. and G. Kirchsteiger (2004). A theory of sequential reciprocity. Games and Economic Behavior 47, 268-298.

Fehr, E., A. Klein, and K. Schmidt (2004). Contracts, fairness and incentives. CESifo Working Paper No. 1215.

Fehr, E. and J. List (2004). The hidden costs and returns of incentives - trust and trustworthiness among ceos. Journal of the European Economic Association 2, 743-771.

Fehr, E. and B. Rockenbach (2003). Detrimental effects of sanctions on human altruism. Nature 422, 137-140.

Fehr, E. and K. M. Schmidt (2004). Fairness and incentives in a multi-task principal agent model. Scandinavian Journal of Economics 106, 453-474.

Gibbons, R. (2004, March). Hold-up (may be your friend). Lecture Note 2, MIT.

Harbring, C. and B. Irlenbusch (2005). Incentives in tournaments with endogenous prize selection. Journal of Institutional and Theoretical Economics 161, 636-663.

Harbring, C., B. Irlenbusch, M. Krakel, and R. Selten (2004). Sabotage in asymmetric contests - an experimental analysis. Bonn Econ Discussion Papers No. 12/2004.

Hart, O. (1995). Firms, Contracts and Financial Structure. Oxford University Press. 
Holmstrom, B. (1999). The firm as a subeconomy. The Journal of Law, Economics and Organization 15, 74-102.

Holmstrom, B. and P. Milgrom (1991). Multitask principal-agent analyses: Incentives contracts, asset ownership, and job design. Journal of Law, Economics $\mathcal{E}$ Organization 7, 24-52.

Jacob, B. and S. Levitt (2003). Rotten apples: An investigation of the prevalence and predictors of teacher cheating. Quarterly Journal of Economics 118, 843-877.

Maddala, G. (1983). Limited-Dependent and Qualitative Variables in Econometrics. New York: Cambridge University Press.

Milgrom, P. (1988). Employment contracts, influence activities and efficient organization design. Journal of Political Economy 96, 42-60.

Milgrom, P. and J. Roberts (1988). An economic approach to influence activities in organizations. American Journal of Sociology 94, S154-S179.

Rajan, R. and L. Zingales (1998). Power in a theory of the firm. Quarterly Journal of Economics 112, 387-432.

Schmidt, K. and M. Schnitzer (1995). The interaction of explicit and implicit contracts. Economics Letters 48, 193-199. 


\section{Appendix A: Derivation of reciprocity equilibria}

In this appendix we formally prove Proposition 1 and Corollary 1. Following Dufwenberg and Kirchsteiger (2004) we assume that the buyer's utility is given by:

$$
U_{B}=m_{B}+Y_{B} \cdot \kappa \cdot \lambda,
$$

with $m_{B}$ denoting the buyer's monetary payoffs and $Y_{B} \cdot \kappa \cdot \lambda$ her reciprocity payoffs. Within this latter term parameter $Y_{B} \geq 0$ captures the buyer's sensitivity towards reciprocity. Factor $\kappa$ reflects the buyer's kindness towards the seller and $\lambda$ the buyer's belief about how kind the seller is to her. We first derive these two factors, which differ for each of the possible investment choices $(p, u)$ the buyer can be confronted with.

Like before, let $b(p, u) \geq 0$ denote the bonus the buyer gives to the seller after seller's choice $(p, u)$. The buyer's kindness $\kappa(b(p, u), p, u)$ of choosing a particular bonus level $b(p, u)$ in response is formally defined as the difference between what the buyer (thinks she) actually gives to the seller by choosing $b(p, u)$ and the average of the minimum and the maximum monetary payoff that she (believes she) could give him in principle. We immediately obtain:

$$
\begin{aligned}
\kappa(b(p, u), p, u)= & w(p, u)-C(p, u)+b(p, u) \\
& -\frac{1}{2} \cdot[w(p, u)-C(p, u)+R(p)-C(p, u)] \\
= & b(p, u)-\frac{1}{2} \cdot[R(p)-w(p, u)]
\end{aligned}
$$

Note that the buyer's kindness is monotonically increasing in the actual bonus paid. Moreover, a given bonus $b(p, u)$ is considered more kind the more the seller can already secure for himself.

Next we turn to $\lambda$, i.e. the perceived kindness of the seller. This factor is defined as the difference between what the buyer believes the seller believes he gives to the buyer by choosing $(p, u)$, and the average of the minimum and the maximum payoff that the buyer believes the seller believes he could give to the buyer in principle. To calculate $\lambda$ we thus need the buyer's second order beliefs about what the seller believes about her bonus payment. Let $b^{\prime}(p, u)$ denote the seller's belief about the buyer's choice of bonus amount $b(p, u)$. Going one level 
up in the belief hierarchy, $b^{\prime \prime}(p, u)$ then gives the buyer's belief about $b^{\prime}(p, u)$. The minimum and maximum amount the buyer believes that the seller believes he could give her then equal, respectively:

$$
\begin{aligned}
k & =\min _{p, u} R(p)-w(p, u)-b^{\prime \prime}(p, u) \\
K & =\max _{p, u} R(p)-w(p, u)-b^{\prime \prime}(p, u)
\end{aligned}
$$

With these expressions the believed kindness of a choice for $(p, u)$ equals:

$$
\lambda(p, u)=R(p)-w(p, u)-b^{\prime \prime}(p, u)-\frac{1}{2} \cdot[k+K]
$$

Expressions (A1) through (A4) characterize the buyer's utility.

We next state and prove three observations that are helpful in proving Proposition 1. Recall that $\bar{p}$ and $\bar{u}$ denote the maximum investment levels. Given the assumptions made in Section 2.1, the buyer's share $R(p)-w(p, u)$ then lies in between the minimum amount of $R(0)-w(0, \bar{u})$ and the maximum amount of $R(\bar{p})-w(\bar{p}, 0)$. Observation 2 below reveals that the higher $R(p)-w(p, u)$, the higher the perceived kindness of a choice for $(p, u)$ is and the higher the corresponding bonus payment $b(p, u)$. In equilibrium investment combination $(0, \bar{u})$ is thus always perceived as the most unkind one and $(\bar{p}, 0)$ as the most kind choice (cf. Observation 3). There is an upper limit to perceived kindness though, and only when this upper bound is attained the buyer may give the seller a positive bonus in equilibrium (Observation 1).

Observation 1. In any SRE necessarily $\lambda(p, u) \leq \frac{1}{Y_{B}}$ and $\lambda(p, u)<\frac{1}{Y_{B}} \Longrightarrow b(p, u)=0$.

Proof. From the expression for the buyer's utility we obtain $\frac{\partial u_{B}}{\partial b}=-1+Y_{B} \cdot \lambda(p, u)$. Suppose $\lambda(p, u)>\frac{1}{Y_{B}}$. Then $\frac{\partial u_{B}}{\partial b}>0$ and the buyer prefers to give the seller the largest possible bonus $b(p, u)=R(p)-w(p, u)$. In equilibrium beliefs are correct, so $b^{\prime \prime}(p, u)=b(p, u)$. With the expression derived for $\lambda(p, u)$ it then follows that $\lambda(p, u)=-\frac{1}{2} \cdot[k+K] \leq 0$, a contradiction. Hence necessarily $\lambda(p, u) \leq \frac{1}{Y_{B}}$. For $\lambda(p, u)<\frac{1}{Y_{B}}$ we obtain $\frac{\partial u_{B}}{\partial b}<0$ and thus necessarily $b(p, u)=0 . \mathrm{QED}$ 
Observation 2. Let $\left(p_{1}, u_{1}\right)$ and $\left(p_{2}, u_{2}\right)$ be such that $R\left(p_{1}\right)-w\left(p_{1}, u_{1}\right)>R\left(p_{2}\right)-w\left(p_{2}, u_{2}\right)$. Then in any $\operatorname{SRE} b\left(p_{1}, u_{1}\right) \geq b\left(p_{2}, u_{2}\right)$ and $\lambda\left(p_{1}, u_{1}\right) \geq \lambda\left(p_{2}, u_{2}\right)$.

Proof. First suppose to the contrary that $b\left(p_{1}, u_{1}\right)<b\left(p_{2}, u_{2}\right)$. Then from expressions $(A 3)$ and (A4) we obtain under correct beliefs $b^{\prime \prime}(p, u)=b(p, u)$ that $\lambda\left(p_{1}, u_{1}\right)>\lambda\left(p_{2}, u_{2}\right)$. By Observation 1 this implies $\lambda\left(p_{2}, u_{2}\right)<\frac{1}{Y_{B}}$ and thus $b\left(p_{2}, u_{2}\right)=0$. Because the bonus is necessarily nonnegative this contradicts the supposition that $b\left(p_{1}, u_{1}\right)<b\left(p_{2}, u_{2}\right)$. Hence $b\left(p_{1}, u_{1}\right) \geq b\left(p_{2}, u_{2}\right)$ necessarily. Next, suppose $\lambda\left(p_{1}, u_{1}\right)<\lambda\left(p_{2}, u_{2}\right)$. Again by Observation 1 we have $b\left(p_{1}, u_{1}\right)=0$. Using $b\left(p_{1}, u_{1}\right) \geq b\left(p_{2}, u_{2}\right)$ we get that also $b\left(p_{2}, u_{2}\right)=0$. But for $b\left(p_{1}, u_{1}\right)=b\left(p_{2}, u_{2}\right)=0$ it necessarily holds that $\lambda\left(p_{1}, u_{1}\right) \geq \lambda\left(p_{2}, u_{2}\right)$ (cf. expression $\left.(A 4)\right)$, a contradiction. QED

Observation 3. In any SRE necessarily $k=R(0)-w(0, \bar{u})$ and $K=R(\bar{p})-w(\bar{p}, 0)-b(\bar{p}, 0)$.

Proof. From Observation 2 follows that the seller's choice of $(p, u)=(0, \bar{u})$ which minimizes $R(p)-w(p, u)$ is considered most unkind. Because $\lambda(0, \bar{u}) \leq 0$ we get $b(0, \bar{u})=0$ from Observation 1 . In equilibrium beliefs are correct, so $b^{\prime \prime}(0, \bar{u})=0$ and we obtain $k=R(0)-w(0, \bar{u})$. Similarly, by Observation 2 a choice for $(p, u)=(\bar{p}, 0)$ is considered most kind. This immediately implies $K=R(\bar{p})-w(\bar{p}, 0)-b(\bar{p}, 0)$. QED

Proof of Proposition 1. $R(p)-w(p, u)$ is maximized for $(p, u)=(\bar{p}, 0)$. From Observation 2 it follows that, if the SRE specifies a positive bonus for some $(p, u)$, necessarily $b(\bar{p}, 0)>0$. First suppose $b(\bar{p}, 0)=0$. In that case $K=R(\bar{p})-w(\bar{p}, 0)$ from Observation 3. Together with $k=R(0)-w(0, \bar{u})$ it follows that $\lambda(\bar{p}, 0)=\frac{1}{2}[(R(\bar{p})-w(\bar{p}, 0))-(R(0)-w(0, \bar{u}))]$. To make $b(\bar{p}, 0)=0$ indeed optimal it is required that $\lambda(\bar{p}, 0) \leq \frac{1}{Y_{B}}$ (cf. Observation 1), i.e. $(R(\bar{p})-w(\bar{p}, 0))-(R(0)-w(0, \bar{u}))-\frac{2}{Y_{B}} \leq 0$. Next let $b(\bar{p}, 0)>0$. From Observation 1 then necessarily $\lambda(\bar{p}, 0)=\frac{1}{Y_{B}}$. With the expressions for $k$ and $K$ in Observation 3 we obtain $\lambda(\bar{p}, 0)=$ $\frac{1}{2}[(R(\bar{p})-w(\bar{p}, 0))-(R(0)-w(0, \bar{u}))]-\frac{b(\bar{p}, 0)}{2}=\frac{1}{Y_{B}}$. This gives that $b(\bar{p}, 0)=[(R(\bar{p})-w(\bar{p}, 0))-$ $(R(0)-w(0, \bar{u}))]-\frac{2}{Y_{B}}$. Using this bonus payment, Observation 3 yields that $K=R(0)-$ $w(0, \bar{u})+\frac{2}{Y_{B}}=k+\frac{2}{Y_{B}}$. By plugging this value into equality $(A 4)$ we obtain $\lambda(p, u)=R(p)-$ $w(p, u)-b(p, u)-(R(0)-w(0, \bar{u}))-\frac{1}{Y_{B}}$ under correct beliefs about $b(p, u)$. From Observation 1 we have $\lambda(p, u) \leq \frac{1}{Y_{B}}$, so necessarily $b(p, u) \geq R(p)-w(p, u)-(R(0)-w(0, \bar{u}))-\frac{2}{Y_{B}}$. Now, 
whenever $b(p, u)>0$ it must hold that $\lambda(p, u)=\frac{1}{Y_{B}}($ cf. Observation 1$)$. In that case $b(p, u)=$ $R(p)-w(p, u)-(R(0)-w(0, \bar{u}))-\frac{2}{Y_{B}}$. This yields expression (2) in the main text.

Given equilibrium bonus payment $b(p, u)$, the optimization problem for the seller becomes:

$$
\begin{aligned}
& \max _{p, u} w(p, u)+b(p, u)-C(p, u)= \\
& \max _{p, u} w(p, u)+\max \left\{0, R(p)-w(p, u)-(R(0)-w(0, \bar{u}))-\frac{2}{Y_{B}}\right\}-C(p, u)
\end{aligned}
$$

First observe that an investment combination for which the max-term is at its kink can never be optimal. This holds because for such investments the right derivative of the seller's payoffs with respect to $p$ equals $r-\frac{\partial C}{\partial p}$, exceeding the left derivative equal to $\pi r-\frac{\partial C}{\partial p}$ whenever $\pi<1$. (For $\pi=1$ we have $w(p, u)=R(p)$ and an investment combination for which the max-term is at its kink does not exist.) Therefore, only two cases have to be considered.

First, assume that $b(p, u)=0$ for the seller's equilibrium investments. Then it immediately follows that $(p, u)=\left(p^{*}, u^{*}\right)$. For the assumption to hold it is required that $Y_{B}<$ $\frac{2}{(1-\pi) r p^{*}+(1-\pi) z\left(\bar{u}-u^{*}\right)}$. Next suppose $b(p, u)=R(p)-w(p, u)-(R(0)-w(0, \bar{u}))-\frac{2}{Y_{B}}$ for the equilibrium investment levels. Then $(p, u)=\left(p_{e f f}, u_{e f f}\right)=\left(\frac{r}{2}, 0\right)$ and it is required that $Y_{B}>$ $\frac{2}{(1-\pi) \frac{r^{2}}{2}+(1-\pi) z \bar{u}}$. Now when $\frac{2}{(1-\pi) \frac{r^{2}}{2}+(1-\pi) z \bar{u}}<Y_{B}<\frac{2}{(1-\pi) r p^{*}+(1-\pi) z\left(\bar{u}-u^{*}\right)}$ both candidates for the optimum exist. The seller's payoffs when choosing $\left(\frac{r}{2}, 0\right)$ equal $\frac{r^{2}}{4}+\pi R+(1-\pi)(Z+z \bar{u})-\frac{2}{Y_{B}}$. A choice for investment combination $\left(p^{*}, u^{*}\right)$ gives $w\left(p^{*}, u^{*}\right)-C\left(p^{*}, u^{*}\right)$. Comparing these two payoffs it immediately follows that when $Y_{B}>(<) \bar{Y}(z, \pi)$ the former is strictly larger (smaller). (When $Y_{B}=\bar{Y}(z, \pi)$ the seller is indifferent between investment combinations $\left(p^{*}, u^{*}\right)$ and $\left(p_{e f f}, u_{e f f}\right)$ and a continuum of equilibria exist.) From $\left[\pi r p^{*}+(1-\pi) z u^{*}-C\left(p^{*}, u^{*}\right)\right] \geq \frac{\pi^{2} r^{2}}{4}$ it follows that $\frac{2}{(1-\pi) \frac{r^{2}}{2}+(1-\pi) z \bar{u}}<\bar{Y}(z, \pi) \leq \frac{2}{(1-\pi) r p^{*}+(1-\pi) z\left(\bar{u}-u^{*}\right)}$. QED

Proof of Corollary 1. We show that the denominator is increasing in $z$ and decreasing in $\pi$. First observe that $M(z, \pi) \equiv\left[\pi r p^{*}+(1-\pi) z u^{*}-C\left(p^{*}, u^{*}\right)\right]$ just equals $w\left(p^{*}, u^{*}\right)-C\left(p^{*}, u^{*}\right)-$ $[\pi R+(1-\pi) Z]$. Because $\left(p^{*}, u^{*}\right)$ maximizes $w(p, u)-C(p, u)$, it also maximizes $[\pi r p+(1-$ $\pi) z u-C(p, u)]$. By the envelope theorem then $\frac{\partial M}{\partial z}=(1-\pi) u^{*}$ and $\frac{\partial M}{\partial \pi}=r p^{*}-z u^{*}$. We obtain $\frac{\partial((1-\pi) z \bar{u}-M)}{\partial z}=(1-\pi)\left(\bar{u}-u^{*}\right)>0$ and $\frac{\partial((1-\pi) z \bar{u}-M)}{\partial \pi}=-r p^{*}-z\left(\bar{u}-u^{*}\right)<0$. QED 